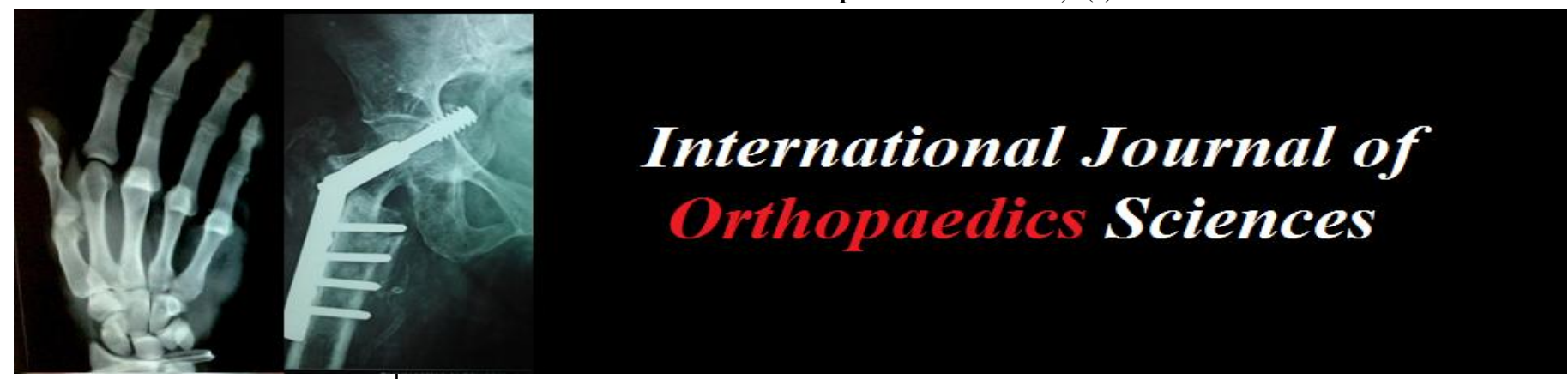

ISSN: $2395-1958$

IJOS 2018; 4(4): 161-163

(C) 2018 IJOS

www.orthopaper.com

Received: 19-08-2018

Accepted: 23-09-2018

Dr. Santosh Borkar

Professor Orthopaedics, Mimer Medical College, Talegaon Dabhade, Pune, Maharashtra, India

\section{Dr. Swapnil Bhise}

Associate Professor,

Orthopaedics, Mimer Medical College, Talegaon Dabhade,

Pune, Maharashtra, India

\section{Dr. Sumit Raghute}

Resident Orthopaedics, Mimer Medical College, Talegaon Dabhade, Pune, Maharashtra, India

Dr. Sidheshwar Thosar Resident Orthopaedics, Mimer Medical College, Talegaon Dabhade, Pune, Maharashtra, India

Dr. Shrirang Godbole Resident Orthopaedics, Mimer Medical College, Talegaon Dabhade, Pune, Maharashtra, India
Correspondence

Dr. Swapnil Bhise

Associate Professor,

Orthopaedics, Mimer Medical

College, Talegaon Dabhade,

Pune, Maharashtra, India

\section{Clinical outcome of single intra articular injection of triamcinolone acetonide depot preparation on knee osteoarthritis}

\author{
Dr. Santosh Borkar, Dr. Swapnil Bhise, Dr. Sumit Raghute, Dr. \\ Sidheshwar Thosar and Dr. Shrirang Godbole
}

DOI: $\underline{\text { https://doi.org/10.22271/ortho.2018.v4.i4c.28 }}$

\begin{abstract}
Oral pharmacological agents are not effective for long term and have many side effects if used for longer period of time. Intraarticular injection of hyaluronic acid injections and other biological agents like bone marrow aspiration concentrate are of still questionable value. Hence till today intraarticular steroid are routinely used in practise in the world all over. Hence we decided to carry out a retrospective review study to assess if the steroids were effective after 24 weeks. A retrospective review study was performed at MIMER Medical College and BSTR Hospital from Jan 2008 to December 2017. Patients with osteoarthritis of knee joint aged 50 years to 80 years of both sexes were included in the study. One thousand and twelve patients were included. We collected data of patients from hospital records. $40 \mathrm{mg}$ of triamcinolone acetonide which is a long acting depot preparation of triamcinolone (potent synthetic corticosteroid which is having selective glucocorticoid activity) was used for intraarticular injection into knee joint under strict antiseptic and aseptic precautions. There was a statistically significant decrease in the initial VAS and WOMAC scores at 3 weeks, 12 weeks and 24 weeks after intraarticular injection $(\mathrm{p}<0.05)$. However we found statistically significant change in VAS \& WOMAC scores over time of 3,12 and 24 weeks if compared to each other $(\mathrm{p}<0.05)$ indicating that pain relieving effect decreases over time. Conclusion: There is sustained and enough pain and functional relief in knee osteoarthritis following a single intraarticular injection of extended release formulation of triamcinolone acetonide injection.
\end{abstract}

Keywords: intraarticular, triamcinolone, acetonide, osteoarthritis, knee

\section{Introduction}

Intraarticular injection of steroids has been studied in the past and reported to be significantly effective but effect is only transitory in nature. Osteoarthritis of knee joint is a major health problem ${ }^{[1]}$. Above 60 yrs of age about $10 \%$ men and $13 \%$ women are affected with OA knee. AAOS (American Association of Orthopedic Surgeons) have recommended a combination of pharmacological and non-pharmacological therapies for $\mathrm{OA}$ knee joint ${ }^{[2]}$. Oral pharmacological agents are not effective for long term and have many side effects if used for longer period of time ${ }^{[2]}$. Intraarticular injection of hyaluronic acid injections and other biological agents like bone marrow aspiration concentrate are of still questionable value ${ }^{[2,3]}$. Hence till today intraarticular steroid are routinely used in practice in the world all over. Commonly given intraarticular steroids are methylprednisolone acetate and triamcinolone acetonide are commonly used in practice ${ }^{[4]}$. Hence we decided to carry out a retrospective review study to assess if the steroids were effective after 24 weeks to relieve pain and whether there were significant side effects. However use of steroids are not without side effects according to literature and steroids are preferred only when other options of pharmacotherapy and physiotherapy are exhausted due to potential side effects described in the literature ${ }^{[4,5]}$.

\section{Materials and Methods}

A retrospective review study was performed at MIMER Medical College and BSTR Hospital from Jan 2008 to December 2017. Patients with osteoarthritis of knee joint aged 50 years to 80 years of both sexes were included in the study. 
Inclusion criteria were unilateral knee pain, radiographic evidence of osteoarthritis, no response to physiotherapy or oral medications.

Exclusion criteria were knee effusion, knee instability, other joint significant swelling, previous intraarticular injection within last one year, history of allergy to drugs, previous history of infection of joint or recent systemic infection, uncontrolled diabetes mellitus or hypertension, malignancy, pregnancy, gross obesity. One thousand and twelve patients were included. We collected data of patients from hospital records. $40 \mathrm{mg}$ of triamcinolone acetonide which is a long acting depot preparation of triamcinolone (potent synthetic corticosteroid which is having selective glucocorticoid activity) was used for intraarticular injection into knee joint under strict antiseptic and aseptic precautions. Injection vials of $1 \mathrm{ml}$ was shaken well before injection to ensure uniform suspension. No local anaesthetic was mixed with injection.

Patient had been followed up every 3 weeks, 12 weeks, 24 weeks after injection.

\section{Results \\ Males 602}

Females 410

Mean age of patients was 63.2 years $+/-9$ years.

Western Ontario \&amp; McMaster Universities Osteoarthritis Index (WOMUOI) which includes 3 subscales (0-20 for pain, 0-8 for stiffness \& amp; 0-68 for physical function) were used in our study with 0-4 for each question.

Mean S.D. was 68.40(27-92) +/-14.4 Low risk WOMAC score (\&lt; $70 \%)$ was there in $70.2 \%$ patients and high risk WOMAC score (\&gt; $70 \%$ ) was there in $29.8 \%$ patients. Mean VAS score was 7.7+/-1.4.

Statistical analysis was performed using SPSS 22.0 software. Non parametric Wilcoxan test was used to compare VAS \&amp; WOMAC scores at 3 weeks, 12 weeks and 24 weeks after injection.

At 3 weeks post injection mean VAS scores and WOMAC scores were $1.9+/-1.8$ and $31.6+/-16.3$ respectively.

At 12 weeks post injection mean VAS scores and WOMAC scores were 3.7+/-2.6 and 46.6+/-19.8 respectively.

At 24 weeks post injection mean VAS scores and WOMAC scores were 5.2+/-2.4 and 58.1+/-19 respectively.

There was a statistically significant decrease in the initial VAS and WOMAC scores at 3 weeks, 12 weeks and 24 weeks after intraarticular injection (p\&lt;0.05). However we found statistically significant change in VAS \&amp; WOMAC scores over time of 3,12 and 24 weeks if compared to each other (p\&lt; 0.05) indicating that pain relieving effect decreases over time.

Septic arthritis was not observed at all and only 3 patients developed steroid induced arthropathy of mild grade. These patients underwent knee joint replacement later.

\section{Discussion}

Osteoarthritis of knee joint has limited treatment options currently oral drugs (NSAIDs, glucosamine, chondroitin sulfate) give only transient relief if et al. ${ }^{[6]}$

Physiotherapy also gives relief in early osteoarthritis and is ill sustained. Intraarticular injections of hyaluronic acid derivatives or platelet rich plasma etc, gives relief in few cases only and is controversial and costly ${ }^{[7]}$. Intraarticular injection of steroids which decreases leucocyte secretion from synovium has been in vogue since many years but there are many reports which associate joint damage with repeated corticosteroid injections ${ }^{[7]}$. However single intraarticular injection is less controversial but claimed to give only few weeks relief ${ }^{[7]}$.

However recently improved and newer corticosteroid injections which are available in depot preparations are claimed to give sustained relief without any significant side effects ${ }^{[8]}$. Triamcinolone acetonide depot preparation is now available in India since many years but till today there are no Indian studies on this which support this.

In our study we got decreased VAS and WOMAC scores after giving single triamcinolone acetonide injection even weeks after surgery. In many patients pain never recurred to pre injection VAS and WOMAC scores. Also there were no significant side effects like joint infection and additional joint damage clinicoradiologically in majority of patients if given in minor OT under aseptic precautions. Only in few (3) cases there was progressive joint damage due to suspected chondrolysis. Overall incidence is just $0.003 \%$. Also depot intraarticular triamcinolone injection is not much costly and easily affordable by most patients. Also if it does not give significant relief, patients still have option to undergo operative treatment like high tibial osteotomy, unicondylar or total knee replacement in future.

Many international studies like those by Kelley SD et al, Williamson et al, Bodick $\mathrm{N}$ et al have reported that Intraarticular, extended release formulations of triamcinolone acetonide is a cost effective therapy for treating osteoarthritis of the knee joint ${ }^{[9,10,11]}$. Our study finding are in accordance with the above studies and even in Indians it is found to be safe and effective to buy time for surgery, for relief for at least few months in those not willing for surgery. Also we got negligible side effects if any with single intraarticular injection of triamcinolone acetonide. We assessed our results based on VAS score and WOMAC scores which are internationally used in such studies ${ }^{[12]}$.

\section{Conclusion}

There is sustained and enough pain and functional relief in knee osteoarthritis following a single intraarticular injection of extended release formulation of triamcinolone acetonide injection.

\section{References}

1. Bijlma JW, Barebaum F, Jafebou FP. Osteoarthritis: an update with relevance for clinical practice. Lancet. 2011; 18:377(9783):2115-26.

2. Hochberg MC, Altman RD, April KT, Binkhalti M, Guyatt G, McGowan J, et al. American College of Rheumatology. American College of Rheumatology 2012 recommendations for the use of non pharmacologic and pharmacological therapies in osteoarthritis of the hand, Hip and Knee. Arthritis Care Res (Hobokn). 2012; 64(4)465-74.

3. Kocnig KM, Ong KL, Lau EC, Vail TP, Burry DJ, Rubash HE et al. The use of hyaluronic acid and hyaluronic acid and corticosteroid injections among medicare patients with knee osteoarthritis J Arthroplasty. 2016; 31(2)351-5. Epub 2015 Aug 29.

4. Raynauld JP, Buckland-Wright C, Ward R, Choguette D, Haraoui B, Martel-Pelletier J et al. Safety and efficacy of long term intraarticular steroid injections in osteoarthritis. Arthritis Rhem. 2003; 48(2):370-7.

5. Chandler GN, Wright V. Deleterious effect of intraarticular hydrocortisone. Lancet. 1958; 27; 2(7048):661-3.

6. Kellgram JH, Lawrence JS. Radiological assessment of 
Osteoarthritis. Ann Rheum Dis. 1951; 16(4):494-502.

7. Jexsuxar D, Donnelly P, Brown GA, Cummins DS. Viscosupplementation for osteoarthritis of the knee. J Bone Joint Surg Am. 2015; 16; 97(24):2047-60.

8. Sweetnam R. Corticosteroid arthropathy and tendon rupture. J Bone Joint Surgery Br. 1969; 51(3):397-8.

9. Conaghan PG, Cohen SB, Bruenbaum F, Lufkin J, Johnson JR, Bodick N. A phase $2 b$ trial of a Novel Extended Release microsphere formulation of Triamcinolone Acetonide for intraarticular injection in knee osteoarthritis.

10. Arthritis Rheumatol, 2017, 31.

11. Kelly SD, Johnson JR, Thornton D, Skaar JR, Varsos GV, Payari FW. An intraarticular, extended release formulation of triamcinolone acetonide as a cost effective therapy for treating osteoarthritis of the knee. Value Health. 2017; 20(5):A145.

12. Williamson TL, Waltz A, Garlick D, Light foot-Dunn R, Schafer K, Kelley S et al. Systemic and local side effects following intraarticular injection of FX006, an extended release, PLGA microsphere formulation of traimcinolone acetonide: results from two nonclinical toxicity studies in dogs. Osteoarthritis cartilage. 2017; 25(11):S431-S432.

13. Bellamy N, Buchanan WW, Goldsmith $\mathrm{CH}$, Campbell J, Stitt LW. Validation study of Womac: a health status instrument for measuring clinically important patient relevant outcomes to antirheumatic drug therapy in patients with osteoarthritis of hip or knee. J Rheumatol. 1986; 15(12):1833-40. 